\title{
Diurnal variation, response to eccentric exercise, and association of inflammatory mediators with muscle damage variables
}

\author{
Mary P. Miles, Jan M. Andring, Sherri D. Pearson, Lindsay K. Gordon, Christine Kasper, \\ Christopher M. Depner, and Jessy R. Kidd \\ Department of Health and Human Development, Montana State University, Bozeman, Montana
}

Submitted 25 May 2007; accepted in final form 9 December 2007

\begin{abstract}
Miles MP, Andring JM, Pearson SD, Gordon LK, Kasper C, Depner CM, Kidd JR. Diurnal variation, response to eccentric exercise, and association of inflammatory mediators with muscle damage variables. J Appl Physiol 104: 451-458, 2008. First published December 13, 2007; doi:10.1152/japplphysiol.00572.2007.—This investigation determined whether inflammatory mediators 1 ) have diurnal variations, 2) respond to high-force eccentric exercise, and 3) associate with markers of muscle damage after high-force eccentric exercise. College-aged men and women $(n=51)$ completed exercise $(3 \times 15$ maximal eccentric elbow flexor actions using 1 arm $)$ and control conditions in random order. Blood was collected preexercise and $4,8,12,24,48$, and $96 \mathrm{~h}$ postexercise. Additional measures included maximal isometric force and midbiceps arm circumference (to detect swelling). Serum and plasma were analyzed for soluble tumor necrosis factor receptor-1 (sTNFR1), IL-6, C-reactive protein, cortisol, and creatine kinase (CK) activity. Relative to the 7:00 AM point in the control condition, diurnal decreases were measured at 12:00 PM and 4:00 PM for IL-6 and at 12:00 PM, 4:00 PM, and 8:00 PM for sTNFR1 and cortisol. sTNFR1, IL-6, CK, swelling, and soreness were higher in the exercise compared with the control condition. The largest of the inflammatory mediator responses was measured for IL-6 $8 \mathrm{~h}$ postexercise in the exercise $(3.00 \pm 3.59 \mathrm{pg} / \mathrm{ml})$ relative to the control condition $(1.15 \pm 0.99 \mathrm{pg} / \mathrm{ml})$. The IL-6 response (time-matched exercise - control concentration) at $8 \mathrm{~h}$ associated $(r>0.282)$ with muscle soreness at 24 and $96 \mathrm{~h}$, and the cortisol response at $8 \mathrm{~h}$ associated $(r>0.285)$ with swelling at 8,24 , and $96 \mathrm{~h}$. Thus soreness and swelling, but not CK and strength loss, had a low association with the inflammatory response following eccentric exercise.
\end{abstract}

interleukin-6; soluble tumor necrosis factor-receptor 1; C-reactive protein; cortisol; creatine kinase

HIGH-FORCE ECCENTRIC EXERCISE has been used widely as a means of inducing muscle damage and may be a valuable tool in the study of inflammation. The muscle-specific inflammatory response is particularly relevant to inflammatory muscle diseases and muscle injury rehabilitation (37). This inflammation also may be important to understanding the development of Type 2 diabetes mellitus (29) and heart disease (25) because muscle is a major component of lean body mass and has a large influence on metabolism. The muscle damage response following highforce eccentric exercise is influenced by the inflammatory process (7). Faulkner et al. (7) characterized the initial damage to sarcomere architecture induced by mechanical forces during eccentric exercise as primary muscle damage and the extension of that damage by inflammatory processes as secondary muscle damage.

Address for reprint requests and other correspondence: M. P. Miles, Montana State Univ., Dept. of Health and Human Development, P.O. Box 173360, Bozeman, MT 59717 (e-mail: mmiles@montana.edu).
The initiation of primary muscle damage induced by highforce eccentric exercise may be fatiguing but is not painful; however, the ensuing inflammatory response leads to delayedonset muscle soreness beginning $8-24 \mathrm{~h}$ after the damage is initiated $(7,18,20)$. Primary muscle tissue damage promotes infiltration by inflammatory cells that, in conjunction with local muscle, endothelial, and satellite cells, produce an array of cytokines to regulate the inflammatory process, including TNF- $\alpha$, IL-1 $\beta$, and IL-6 $(4,26,31,34)$. Typical responses to muscle injury induced by eccentric exercise include loss of force-generating capacity, decreased range of motion, delayedonset muscle soreness or tenderness, swelling, and delayed increases in circulating intramuscular proteins, e.g., creatine kinase (CK), myoglobin, troponin, or myosin heavy chain proteins $(11,13,15,20,21,24,30,31,33,36,38)$. These are considered indirect markers of muscle damage. Direct measurement of muscle damage may be made by collecting muscle biopsies and visually assessing fiber damage through histological or electron microscopy techniques $(34,37)$. Loss of maximal voluntary contraction force is considered one of the best methods for quantifying muscle injury, including both direct and indirect assessment techniques $(7,37)$. However, whether force loss results solely from primary (that induced by mechanical force) or from both primary and secondary muscle damage (that induced by inflammation) is not known.

The relationship between markers of muscle injury induced by eccentric exercise and indications of inflammation is complicated and inconsistent across investigations. Events of both the muscle damage and inflammatory responses occur in a specific order with peaks and durations that vary among individuals. Association between various inflammatory and muscle damage measures at different postexercise time points has been reported in many $(3,8)$ but not all investigations (10). After high-force eccentric exercise, inflammatory cytokines appear in skeletal muscle before inflammatory cells arrive, and these events precede the peak of muscle fiber disruption measured using a variety of histological techniques to directly measure damage (34). IL-6 has many regulatory roles in the inflammatory process, including feedback inhibition of the "alarm" cytokines that initiate the inflammatory process (IL-1 $\beta$ and $\mathrm{TNF}-\alpha$ ), and feedforward induction of anti-inflammatory mediators [IL-1 receptor antagonist (IL-1ra), IL-10, and cortisol] and acute-phase proteins [C-reactive protein (CRP)] (17). Correlations between postexercise IL-6 levels and serum CK activity (3) and muscle soreness (15) have been measured in previous investigations; however, similar IL-6 responses were

The costs of publication of this article were defrayed in part by the payment of page charges. The article must therefore be hereby marked "advertisement" in accordance with 18 U.S.C. Section 1734 solely to indicate this fact. 
measured following two separate bouts of eccentric exercise in which all markers of muscle damage were substantially diminished following the second bout, an occurrence known as the repeated bout effect (38).

The purposes of this investigation were to determine 1 ) whether diurnal variations occur for selected inflammatory mediators and CRP, 2) the magnitude and time course of plasma inflammatory mediator and CRP increases after high-force eccentric exercise, and 3) whether the magnitude of those changes is associated with markers of muscle damage (strength loss, soreness, swelling, and increased CK). To achieve these purposes we chose a mediator of the early activation of the inflammatory response (soluble tumor necrosis factor receptor 1, sTNFR1), a mediator in the middle of the inflammatory cascade with both feedback and feedforward roles (IL-6), an acute-phase protein to identify inflammation at the systemic level (CRP), and an immunoregulatory hormone that influences whole body metabolism and diurnal variations (cortisol). We hypothesize that there is a delayed increase in inflammatory mediators following high-force eccentric exercise and that the magnitude of inflammatory responses will be greater when indirect indications of muscle damage are greater. Unlike previous studies, our research design included a nonexercising control condition to account for diurnal variations. These findings will help to clarify the relationship between inflammatory mediators and processes related to muscle tissue injury.

\section{EXPERIMENTAL PROCEDURES}

Participants. Male and female non-weight-trained individuals $(n=$ 51 ) between 18 and $40 \mathrm{yr}$ of age completed this investigation and were included in the final data analysis (Table 1). Individuals who reported performing activities in which lifting and lowering of heavy objects was performed, or who recalled experiencing muscle soreness in the arm muscles at any time in the 6 mo preceding the investigation, were excluded from participation. The aim of these criteria was to eliminate confounding influences of the repeated bout effect, in which muscle that has been exposed to high-force eccentric exercise will have a blunted muscle damage response to subsequent eccentric exercise bouts that occur within the next several months (22). Additional exclusion criteria included known anemia, musculoskeletal limita-

Table 1. Descriptive characteristics, baseline inflammatory mediator concentrations and creatine kinase activity, and order of experimental conditions for participants

\begin{tabular}{lccc}
\hline \hline & Men $(n=29)$ & Women $(n=22)$ & $P$ Value \\
\hline Stature, m & $1.79 \pm 0.06$ & $1.68 \pm 0.06$ & 0.00 \\
Mass, kg & $69.6 \pm 11.0$ & $73.1 \pm 13.2$ & 0.05 \\
Physical activity, & & & \\
$\quad$ low/moderate/high & $4 / 14 / 9^{*}$ & $0 / 9 / 11^{*}$ & 0.11 \\
CRP, mg/l & $1.11 \pm 2.62$ & $3.09 \pm 4.40$ & 0.02 \\
IL-6, pg/ml & $1.62 \pm 1.24$ & $1.56 \pm 1.93$ & 0.36 \\
sTNFR1, pg/ml & $1,224 \pm 166$ & $1,168 \pm 197$ & 0.28 \\
Cortisol, $\mu \mathrm{g} / \mathrm{dl}$ & $33.7 \pm 9.2$ & $43.4 \pm 11.3$ & 0.00 \\
CK, IU/l & $173.3 \pm 82.1$ & $110.3 \pm 30.4$ & 0.00 \\
Order of conditions, & & & \\
$\quad$ EX 1st/CON 1st & $15 / 14$ & $11 / 11$ & \\
\hline
\end{tabular}

Values are means $\pm \mathrm{SD} . P$ value is for independent samples $t$-test for continuous variables and for chi square statistic for categorical data (physical activity). CRP, C-reactive protein; sTNFR1, soluble tumor necrosis factor receptor 1; CK, serum creatine kinase activity; IU, international units; EX, exercise condition; CON, control condition. *Questionnaires invalidated for 2 participants. tions, known inflammatory conditions, diabetes, heart disease, known kidney problems (excluding kidney stones), smoking, alcohol use greater than one drink per day for women and two drinks per day for men, binge alcohol drinking (greater than 4 drinks on a single occasion), chronic use of anti-inflammatory medications (including over-the-counter nonsteroidal anti-inflammatory drugs), lipid-lowering medications, regular performance of physical activity in which muscle soreness or bruising occurs, and pregnancy. The research protocol and informed consent document for this investigation were approved by the Human Subjects Committee at Montana State University. Participants were informed of the procedures and potential risks associated with the study and gave written informed consent before participation in this investigation.

Experimental protocol. Participants performed both an exercise (EX) and a control $(\mathrm{CON})$ protocol in randomized order with equal numbers beginning in each of the two conditions to avoid a confounding effect of order (Table 1). The EX protocol consisted of baseline assessments at 7:00 AM, followed by a bout of high-force eccentric resistance exercise using the elbow flexor muscles of the nonpreferred limb (according to self-reported handedness), and followup assessments 4, 8, 12, 24, 48, 96, and $120 \mathrm{~h}$ postexercise. Assessments included muscle soreness, midbrachial arm circumference, blood collection for blood-borne variables, and maximal force production. The nonexercised arm was measured as a CON for arm circumference and maximal force production. A time-matched CON condition identical to the experimental condition but without the high-force eccentric exercise was performed for blood-borne variables. The experimental and control protocols were separated by 3-6 wk in most instances.

Several restrictions were placed on participants to minimize variability in physiological status. Standardized conditions for blood collections in the morning included an overnight fast and minimal physical activity before reporting to the laboratory at 7:00 AM for blood collection and assessments. Strenuous physical exercise, that judged to be near maximal in intensity or longer than $60 \mathrm{~min}$ in duration, was not allowed during the course of the exercise and blood collection protocols. To minimize the influence of cyclical hormonal variations, all women in the study began each exercise and control protocol within 4 days of the onset of menstrual bleeding. Additionally, to avoid the influence of illness on inflammatory parameters, participants were only tested if they were free of known infection for at least $1 \mathrm{wk}$.

Physical activity questionnaire. To assess physical activity, participants completed a short-format recall of their physical activity over the previous 7 days using the International Physical Activity Questionnaire (IPAQ) (6). According to the classification system of the IPAQ, individuals in the high category perform vigorous physical activity at least 3 days/wk or moderate to vigorous activity 7 days/wk, individuals in the moderate category perform 3-5 days of moderate or vigorous activity in the range of 20-30 $\mathrm{min} /$ day, and individuals in the low category did not meet the criteria for the moderate category.

Post hoc inclusion criteria for comparison of EX and CON conditions. After laboratory and exercise, data were collected for all participants who completed the exercise protocol $(n=60)$. Participants who were not stable in their baseline CRP concentrations $(n=9)$ were excluded from data analyses, leaving a final pool of $n=51$ participants. CRP stability was defined as either having both preexercise concentrations below $2.0 \mathrm{mg} / \mathrm{l}$ or within a threefold range. This provision was necessary to ensure that underlying inflammation was not present during one of the two conditions.

High-force eccentric exercise. The protocol for inducing muscle damage in the flexor muscles (primarily the biceps brachii and the brachialis) of the nonpreferred arm was performed using a computercontrolled, isokinetic dynamometer (Kin Com125 E+, Chattecx, Chattanooga, TN). The dynamometer was adjusted to the body height and limb length of the individual. The arm was supported by a padded bench at $\sim 0.79 \mathrm{rad}$ of shoulder abduction, the axis of rotation of the 
dynamometer was aligned with the axis of rotation of the elbow, and the forearm was secured to the lever arm of the dynamometer with padded support just proximal to the wrist joint. Three sets of 15 repetitions of eccentric elbow flexion were performed with maximal effort at a rate of one repetition per $15 \mathrm{~s}$ and 5 min rest between sets. Repetitions began with the elbow fully flexed and ended with the elbow fully extended. Using maximal effort, participants attempted to keep the elbow in the fully flexed position as the dynamometer pulled the arm to a fully extended position at an angular velocity of 0.79 $\mathrm{rad} / \mathrm{s}$. The dynamometer returned the arm to the fully flexed position and paused for $10 \mathrm{~s}$ before beginning the next repetition. Participants were verbally encouraged to give a maximal effort with each repetition.

Maximal force production. Maximal isometric force production for elbow flexion at an enclosed elbow angle of $1.57 \mathrm{rad}$ was measured before, immediately following, and $24,48,96$, and $120 \mathrm{~h}$ postexercise. To perform the isometric strength measurement, the dynamometer and subject position were adjusted as for the high-force eccentric exercise, and the lever arm was fixed such that the elbow was positioned with a 1.57-rad angle. Participants were instructed to pull (flex) for $3 \mathrm{~s}$ using maximal effort. Three maximal efforts were performed with $30 \mathrm{~s}$ rest between repetitions. To ensure uniformity of measurements from day to day, all dynamometer position settings for each subject were recorded and reproduced at each testing session. To eliminate variation due to initial strength levels, data were converted to percentages of the initial strength measurement before analysis.

Muscle soreness and swelling. A subjective assessment of muscle soreness was made by participants using a 100-mm visual analog scale anchored at one end with "no soreness" and at the other end with "very, very sore." Participants were instructed to fully flex and extend the elbow while holding a 1-kg weight and gently squeezing the elbow flexor muscles, and then to place a tick mark on the analog scale that represented the degree of soreness. Participants also were instructed to think of their ratings in terms of muscle soreness, not of fatigue or relative to other types of pain, e.g., a broken bone. Swelling was assessed by measuring the circumference of the midbrachium (midbiceps) and at a point approximately halfway between the midbiceps and the axis of rotation of the elbow using a spring-loaded anthropometric tape measure. The point of maximal girth of the biceps brachii muscle was palpated in a flexed position, and three ink dots were placed on the arm in a plane perpendicular to the axis of the limb. These marks were maintained throughout the protocol and used to guide consistent tape measure placement.

Blood collection and analysis. Participants sat for 10-15 min before blood was collected from an antecubital vein into evacuated tubes using a standard venipuncture technique. Blood was collected in a vacuum tube without additive for analysis of CRP, cortisol, and CK; and containing EDTA for IL-6 and sTNFR1. After clotting, serum was separated from cells using a refrigerated 21000R Marathon centrifuge (Fisher Scientific, Pittsburgh, PA). All samples were stored at $-80^{\circ} \mathrm{C}$ until analysis.

Serum CRP (high-sensitivity assay, MP Biomedicals, Irvine, CA), plasma IL-6 (high-sensitivity assay, R\&D Systems, Minneapolis, MN), plasma sTNFR1 (R\&D Systems), and serum cortisol (Diagnostic Systems Laboratories, , Webster, TX) concentrations were measured using commercially available ELISA kits according to the instructions of the manufacturers. Absorbance of 96-well assay plates was read using a $\mu$ Quant Universal microplate spectrophotometer (Bio-Tek Instruments, Winooski, VT). All samples were run in duplicate. Average intra-assay coefficients of variation $(\mathrm{CV})$ for CRP, IL-6, sTNFR1, and cortisol were $11.0 \%, 7.6 \%, 3.8 \%$, and $3.4 \%$, respectively. Based on the anticipated time course for changes in these variables and the need to identify potential diurnal variations throughout the day, CON samples were measured for the first $24 \mathrm{~h}$ postexercise only for these variables.

Serum CK activity was measured using an ultraviolet, kinetic assay at $37^{\circ} \mathrm{C}$ (Thermo Scientific, Waltham, MA). The assay was modified for microplate analysis and read using a $\mu$ Quant Universal microplate spectrophotometer (Bio-Tek Instruments). Samples were run in duplicate, and all samples for a given participant were run in the same assay. The intra-assay CV was $4.5 \%$.

Statistical analysis. Data were analyzed using SPSS for Windows (version 13.0, SPSS, Chicago, IL). Baseline measures were compared between sexes using an independent $t$-test for continuous variables and chi-square analysis for categorical variables (physical activity). Baselines for inflammatory variables were the mean of the initial values for the EX and CON conditions. Nonnormally distributed variables CRP, IL-6, and CK were log transformed before all analyses. A general linear model two-way repeated measures ANOVA was used to compare conditions (EX and $\mathrm{CON}$ ) over time. The Greenhouse-Geisser adjustment to degrees of freedom was used when the assumption of sphericity was violated. Post hoc analysis to determine the location of differences when significant main effects or interactions were detected was performed using paired $t$-tests with Bonferroni $\alpha$-adjustment within conditions over time and between conditions at each time point. There is controversy regarding the existence of sex differences in the response to eccentric exercise with some studies reporting sex differences and others reporting no difference (5); therefore, analyses including sex as a grouping variable were run to determine whether or not male and female participants could be collapsed in the ANOVA. With the exception of cortisol, there were no sex differences in the inflammatory variables. For cortisol, the differences were derived from the higher baseline of the women rather than condition by time interaction. Thus both sexes were collapsed in the ANOVA and correlation analyses. Associations were measured using Pearson product-moment correlations. Correlation coefficients were determined for all variables using either the raw or log-transformed values as indicated, and for the exercise-induced inflammatory responses (time-matched EX - CON values). Statistical significance was set at the $\alpha=0.05$ level.

\section{RESULTS}

Anthropometric and baseline inflammatory characteristics are divided by sex and presented in Table 1. Male participants were taller and had higher baseline serum CK activity than female participants. Female participants had higher baseline levels of both CRP and cortisol. Physical activity levels were predominately moderate to high for both sexes. Thus, based on our inclusion criteria and the IPAQ data, our participants may be described as non-weight-trained individuals with primarily moderate to high levels of physical activity attained through work and leisure activities.

Indirect markers of muscle damage were elevated in the EX compared with the CON arm or condition (Table 2). Maximal isometric force was lower $\left(F_{1,5}=49.42, P<0.001\right)$ in the EX arm compared with $\mathrm{CON}$ arm at all postexercise time points. $\mathrm{EX}$ and $\mathrm{CON}$ arm circumferences at the midbiceps level were measured to assess swelling. Percent change relative to preexercise was higher $\left(F_{1,6}=3.78, P<0.001\right)$ in the EX compared with the CON arm 48 and $96 \mathrm{~h}$ postexercise. Ratings of muscle soreness increased $\left(F_{6}=69.52, P<0.001\right)$ from 4 to $48 \mathrm{~h}$ and were above preexercise levels through $96 \mathrm{~h}$ postexercise. Finally, serum CK activity was higher (interaction $P<0.001$ ) in the EX compared with the CON condition from 24 to $96 \mathrm{~h}$ postexercise.

Diurnal variations were measured in sTNFR1, IL-6, and cortisol. There was a strong diurnal fluctuation in STNFR1 with the highest concentrations at 7:00 AM and lower $\left(F_{4}=62.70\right.$, $P<0.001$ ) concentrations at 12:00, 4:00, and 8:00 PM (Fig. 1A). A slight diurnal decrease in IL-6 was detected at 4 and $8 \mathrm{~h}$ 
Table 2. Indicators of muscle damage in the control and exercise conditions

\begin{tabular}{|c|c|c|c|c|c|c|c|}
\hline & \multicolumn{7}{|c|}{ Time } \\
\hline \multicolumn{8}{|c|}{ Strength loss, \% } \\
\hline Exercise & $-31.4 \pm 20.4 *$ & & & & $-27.5 \pm 22.0^{*}$ & $-24.1 \pm 23.9 *$ & $-11.2 \pm 27.3^{*}$ \\
\hline \multicolumn{8}{|c|}{ Soreness, $\mathrm{mm} / 100 \mathrm{~mm}$} \\
\hline Exercise & $2.1 \pm 5.5$ & $12.4 \pm 13.1 \dagger$ & $13.8 \pm 15.9 \dagger$ & $18.3 \pm 15.1 \dagger$ & $37.9 \pm 20.8 \dagger$ & $47.2 \pm 23.1 \dagger$ & $20.1 \pm 20.4 \dagger$ \\
\hline \multicolumn{8}{|c|}{ Serum CK, IU/1 } \\
\hline Control & $153 \pm 93$ & & & & $149 \pm 80$ & $148 \pm 80$ & $144 \pm 70$ \\
\hline Exercise & $139 \pm 62$ & & & & $247 \pm 221^{*}$ & $466 \pm 856^{*}$ & $2,133 \pm 5,082 *$ \\
\hline
\end{tabular}

Values are mean $\pm \mathrm{SD}$. Values at $0 \mathrm{~h}$ were measured immediately postexercise. $* P<0.007$ compared with control condition. $\dagger P<0.007$ compared with preexercise.

(12:00 and 4:00 PM) in the CON condition (Fig. 1B). A strong diurnal variation was measured in cortisol with decreased $\left(F_{4}\right.$ $=219.96, P<0.001)$ concentrations at 4,8 , and $12 \mathrm{~h}(12: 00$, 4:00, and 8:00 PM) (Fig. 2B).

Postexercise concentrations of sTNFR1 and IL-6 were higher in EX compared with CON condition. sTNFR1 was higher $\left(F_{1}=5.06, P<0.05\right)$ in the EX compared with the CON condition (Fig. 1A). Relative to the CON condition, IL-6 was higher $\left(F_{1,4}=16.38, P<0.001\right) 4$ to $12 \mathrm{~h}$ postexercise with a clear peak at $8 \mathrm{~h}$ postexercise during the EX condition (Fig. 1B). CRP increased in the EX compared with the CON condition $\left(F_{1,4}=3.87, P<0.05\right)$, but differences did not reach significance after adjustment (Fig. 2A). Similarly, an interaction $\left(F_{1,4}=2.45, P<0.05\right)$ between $\mathrm{EX}$ and $\mathrm{CON}$ conditions
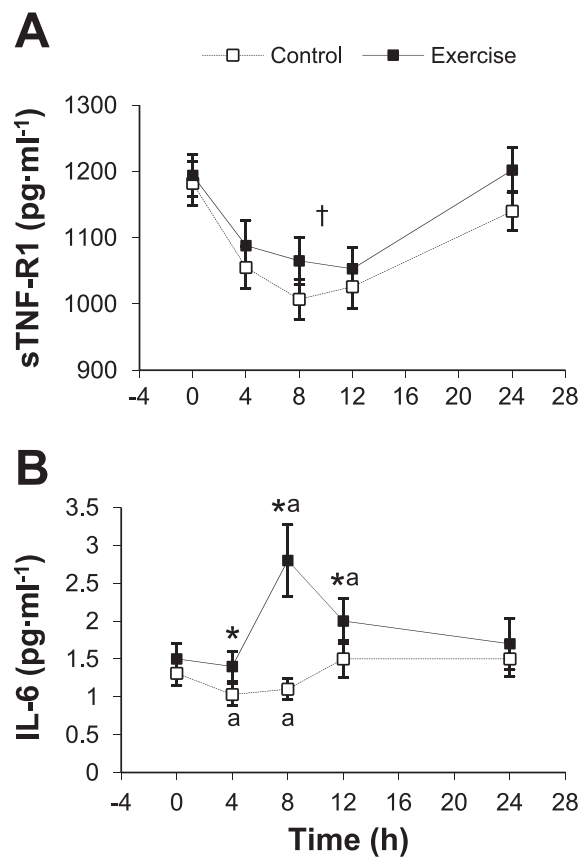

Fig. 1. Plasma soluble tumor necrosis factor receptor-1 (sTNFR1; A) and IL-6 $(B)$ concentrations following eccentric exercise in the exercise and control conditions. Values are means \pm SE. $* P<0.0036$ compared with the control condition. ${ }^{a} P<0.0036$ compared with preexercise within condition. $\dagger P<$ 0.05 main effect for exercise condition compared with control condition. was detected for cortisol concentration, but differences were not significant after adjustment (Fig. 2B).

There was a consistent association among concentrations of several of the inflammatory variables over time but only one association between inflammatory and muscle damage variables (Table 3). IL-6 associated with CRP and sTNFR1 at most time points, excluding the 8-h time point when there was a spike in IL-6 concentrations. Cortisol concentrations associated with CRP at most time points, but not IL-6 or sTNFR1. In contrast, the only significant association between inflammatory and muscle damage variables was measured between IL-6 and soreness at 8 and $24 \mathrm{~h}$. However, some associations were measured between inflammation and muscle damage variables at asynchronous time points (Table 4). The IL-6 response at $8 \mathrm{~h}$ postexercise associated with soreness at 24 and $96 \mathrm{~h}$. The cortisol response at $8 \mathrm{~h}$ associated with swelling at 8 through
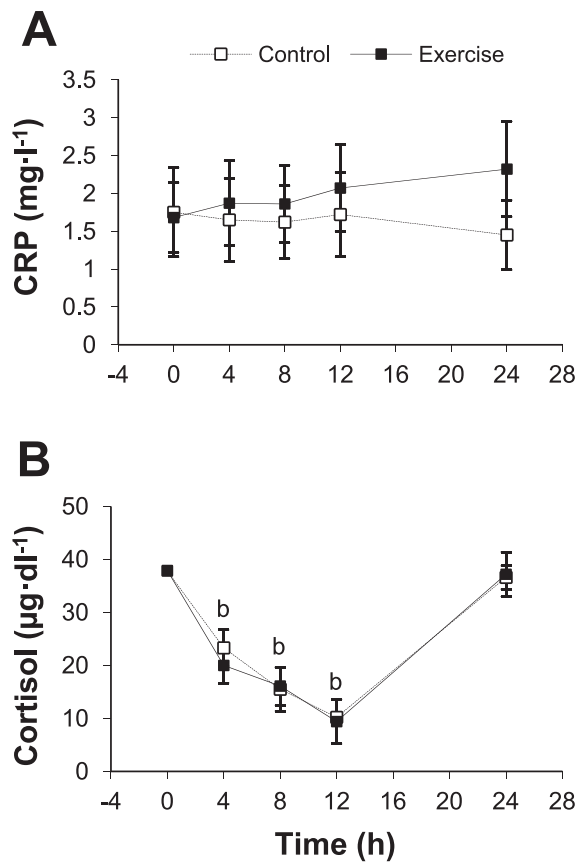

Fig. 2. Serum C-reactive protein $(\mathrm{CRP} ; A)$ and cortisol $(B)$ concentrations after eccentric exercise in the exercise and control conditions. Values are means \pm SE. ${ }^{b} P<0.0036$ compared with preexercise. 
Table 3. Pearson product-moment correlations between inflammatory and muscle damage variables within each time point measured

\begin{tabular}{|c|c|c|c|c|c|c|c|}
\hline Variable & \multicolumn{7}{|c|}{ Time } \\
\hline \multicolumn{8}{|c|}{ Variable: $\ln I L-6$} \\
\hline Cortisol & 0.234 & 0.242 & 0.208 & -0.038 & 0.163 & 0.248 & \\
\hline sTNFR1 & $0.278^{*}$ & $0.342 *$ & 0.108 & $0.344 *$ & $0.400 \dagger$ & $0.290 *$ & \\
\hline $\operatorname{lnCRP}$ & $0.375 \dagger$ & $0.448 \dagger$ & 0.181 & $0.498 \dagger$ & $0.431 \dagger$ & $0.508 \dagger$ & \\
\hline Soreness (mm) & 0.175 & 0.146 & $0.319^{*}$ & 0.266 & $0.287 *$ & 0.261 & \\
\hline Arm circumference (\%change) & & 0.011 & -0.014 & 0.126 & 0.017 & 0.217 & \\
\hline \multicolumn{8}{|c|}{ Variable: Cortisol } \\
\hline sTNFR1 & -0.046 & 0.196 & 0.016 & -0.074 & -0.169 & -0.086 & $-0.288^{*}$ \\
\hline $\operatorname{lnCRP}$ & $0.320^{*}$ & 0.251 & $0.321 *$ & 0.042 & $0.386 \dagger$ & $0.385 \dagger$ & $0.277^{*}$ \\
\hline Soreness (mm) & 0.129 & -0.049 & 0.240 & 0.112 & 0.233 & 0.084 & -0.133 \\
\hline $\operatorname{lnCK}(\mathrm{IU} / \mathrm{l})$ & 0.002 & & & & -0.193 & -0.062 & -0.220 \\
\hline $\operatorname{lnCRP}$ & 0.191 & 0.242 & 0.206 & 0.212 & 0.261 & 0.225 & 0.174 \\
\hline Soreness (mm) & 0.045 & -0.043 & -0.030 & -0.028 & -0.145 & 0.014 & 0.092 \\
\hline $\operatorname{lnCK}(\mathrm{IU} / \mathrm{l})$ & 0.110 & & & & 0.160 & 0.084 & 0.128 \\
\hline Strength loss $(\%)$ & 0.081 & & & & 0.178 & -0.011 & -0.182 \\
\hline Arm circumference (\%change) & & 0.129 & 0.257 & 0.008 & 0.079 & 0.046 & 0.144 \\
\hline \multicolumn{8}{|c|}{ Variable: $\ln C R P$} \\
\hline Soreness (mm) & 0.055 & -0.045 & -0.019 & 0.142 & 0.271 & 0.186 & 0.000 \\
\hline $\operatorname{lnCK}(\mathrm{IU} / \mathrm{l})$ & -0.014 & & & & -0.047 & -0.064 & 0.068 \\
\hline Strength loss $(\%)$ & -0.146 & & & & -0.106 & -0.017 & -0.144 \\
\hline Arm circumference (\%change) & & 0.046 & 0.051 & -0.056 & -0.095 & -0.096 & -0.064 \\
\hline
\end{tabular}

lnIL-6 is log-normalized IL-6, lnCRP is log-normalized CRP, and $\operatorname{lnCK}$ is log-normalized CK. $* P<0.05, \dagger P<0.01$.

$96 \mathrm{~h}$ postexercise. Taken as a whole, associations between the plasma concentrations or responses (time-matched EX - CON concentrations) of inflammatory mediators and the indicators of muscle damage were weak.

\section{DISCUSSION}

This investigation sought to identify whether the selected inflammatory mediators 1 ) vary over the course of the day in a diurnal pattern, 2) increase following high-force eccentric exercise, and 3) associate with muscle damage indicators following eccentric exercise. In the CON condition, we detected diurnal decreases in IL-6, sTNFR1, and cortisol at 12:00, 4:00, and 8:00 PM relative to 7:00 AM. Using a model of high-force eccentric exercise of a relatively small muscle mass, we measured higher sTNFR1 and IL-6 during the EX compared with the CON condition, but no significant differences between conditions for CRP and cortisol. Contrary to our hypothesis, sTNFR1, IL-6, cortisol, and CRP responses after exercise were independent of the magnitude of change in strength loss. However, consistent with our hypothesis, IL-6

Table 4. Pearson product-moment correlation coefficients between selected exercise-induced inflammatory responses and muscle damage variables

\begin{tabular}{|c|c|c|c|c|c|c|c|}
\hline \multirow[b]{2}{*}{ Variable } & \multicolumn{7}{|c|}{ Time } \\
\hline & $0 \mathrm{~h}$ & $4 \mathrm{~h}$ & $8 \mathrm{~h}$ & $12 \mathrm{~h}$ & $24 \mathrm{~h}$ & $48 \mathrm{~h}$ & $96 \mathrm{~h}$ \\
\hline \multicolumn{8}{|c|}{$I L-6$ response at $8 h$ postexercise } \\
\hline Soreness (mm) & 0.032 & 0.194 & 0.228 & 0.250 & $0.282 *$ & 0.248 & $0.302 *$ \\
\hline CK (IU/l) & 0.003 & & & & -0.033 & -0.037 & 0.065 \\
\hline Strength loss $(\%)$ & -0.007 & & & & -0.124 & -0.149 & 0.016 \\
\hline Arm circumference (\%change) & & -0.149 & 0.054 & 0.057 & 0.166 & 0.151 & 0.072 \\
\hline \multicolumn{8}{|c|}{ Cortisol response at $8 \mathrm{~h}$ postexercise } \\
\hline Soreness (mm) & -0.10 & -0.023 & 0.016 & -0.011 & -0.021 & -0.019 & 0.124 \\
\hline $\mathrm{CK}(\mathrm{IU} / \mathrm{l})$ & -0.025 & & & & 0.004 & 0.022 & 0.057 \\
\hline Strength loss (\%) & 0.022 & & & & 0.129 & -0.004 & 0.174 \\
\hline Arm circumference (\%change) & & 0.054 & $0.337 *$ & 0.267 & $0.285^{*}$ & $0.413 \dagger$ & $0.299 *$ \\
\hline
\end{tabular}

"Response" $=$ time-matched exercise value minus control value. $* P<0.05, \dagger P<0.01$. 
associated with perceptions of muscle soreness and cortisol associated with swelling, but the level of association was low. Thus, while some plasma inflammatory mediators are higher after high-force eccentric exercise, these mediators explain very little of the large variability in typical indicators of muscle damage.

We detected a pattern of diurnal variation with decreases at 12:00, 4:00, and 8:00 PM relative to 7:00 AM for sTNFR1 and cortisol. A diurnal decrease was detected at 12:00 and 4:00 PM relative to 7:00 AM for IL-6. Cortisol is considered to be the primary neuroendocrine modulator of diurnal variations in immune function, and the well-documented diurnal variations of cortisol influence in vitro production of several cytokines in a pattern inversely related to the variation of cortisol $(12,27$, 28). However, in vivo diurnal variations in plasma levels have been more difficult to detect and more complex than in vitro responses given the vast array of potential influences and the potential for negative-feedback modulation. We found a parallel rather than reciprocal pattern in sTNFR1 and IL-6 relative to cortisol. While in vivo diurnal variations in TNF- $\alpha$ and sTNFR2 (the p75 TNF-receptor) are well documented $(9,14)$, diurnal variation for sTNFR1 (the p55 TNF receptor) has been detected in the present investigation and some (9) but not all other investigations (14). IL-6 diurnal variations in vivo have been poorly characterized in previous investigations, but some evidence of higher levels during sleep and a nadir around 9:00 AM have been reported $(12,35)$. We measured higher plasma IL-6 concentrations at 7:00 AM relative 12:00 and 4:00 PM. Had we measured at 9:00 AM, we may have detected a larger decrease than from 7:00 AM to 12:00 PM, but the overall patterns are compatible between studies. CRP did not vary by time of day, and this is consistent with previous research (16). These findings highlight the need for careful control of time of day in data collection for all studies of inflammation and a control condition in many research designs.

Higher concentrations of sTNFR1 and IL-6 after high-force eccentric exercise suggest that the inflammatory cascade was initiated by the eccentric exercise and detectable in the circulation several hours after the completion of the exercise. Higher sTNFR1 in the EX compared with the CON condition reflects activation of the TNF- $\alpha$ system over the first $24 \mathrm{~h}$ postexercise and is consistent with previous investigations of eccentric exercise $(24,33)$. sTNFR1 enters the circulation within minutes of TNF- $\alpha$ appearance in the plasma to prolong its half-life from 6 min to more than $2.5 \mathrm{~h}(1,2)$. We measured a spike of IL-6 increase in the plasma that peaked $\sim 8 \mathrm{~h}$ postexercise and returned to preexercise levels by $24 \mathrm{~h}$ postexercise. This 8-h peak in IL-6 concentrations is consistent with earlier work from our laboratory (19), occurs later than reported in previous studies $(3,15,23,33,38)$, but is consistent with intramuscular IL-6 expression that peaked $8-12 \mathrm{~h}$ following high-force eccentric exercise (34). CRP was the least consistent of the responses and was not higher during the EX condition. Paulsen et al. (23) detected small elevations in CRP from 23 to $95 \mathrm{~h}$ with a sustained peak from 23 to $47 \mathrm{~h}$ following high-force eccentric exercise consisting of 300 repetitions with the knee extensor muscles. The lack of response in the present study may be attributed to a lesser stimulus applied to smaller muscle mass. One of the physiological roles of IL-6 is to induce release of cortisol to the circulation, and exercise-induced changes in cortisol have been linked to IL-6
(26). The relatively small increase in IL-6 measured postexercise was not sufficient to induce a measurable change in cortisol.

Time-matched associations between inflammation and muscle damage indicators were detected for IL-6. IL-6 and muscle soreness correlated at 8 and $24 \mathrm{~h}$ after exercise, providing a link between inflammation and soreness onset. We did not find an association between IL- 6 and CK. While previous investigations have measured associations between IL-6 2-4 h with CK activity 2-7 days after eccentric exercise $(3,33)$, the importance of a relatively small IL-6 response early in recovery from exercise to the very large increase in CK activity days after the eccentric exercise has been questioned (33). Inflammation and muscle damage are both processes in which events occur in a specific order with the potential for early events to influence the magnitude of subsequent events. Thus the relationship among variables may be asynchronous rather than time matched. For example, the peak in plasma IL-6 concentration occurs well before peak soreness, swelling, and serum CK activity. Furthermore, the variable of interest may not be the absolute level of inflammatory mediators but the amount of change induced by the exercise bout. Some association between inflammation and muscle damage indicators was measured using inflammation responses (EX - CON concentration at a given time point) and asynchronous time points. The response of IL- $68 \mathrm{~h}$ postexercise correlated with soreness at 24 and $96 \mathrm{~h}$ postexercise. Given the sequence of tissue injury, early release of TNF- $\alpha$ and IL- $1 \beta$, followed by production of IL-6, levels of plasma IL-6 $8 \mathrm{~h}$ postexercise may be an indication of the amount of inflammation occurring in the exercised tissue. Thus the inflammatory events leading to the rise in IL-6 $8 \mathrm{~h}$ postexercise associated with subsequent perceptions of soreness. This is consistent with muscle soreness as an indication of secondary muscle damage induced by inflammation. Cortisol is a key neuroendocrine modulator of the immune system with effects that tend to be anti-inflammatory (17). The cortisol response at $8 \mathrm{~h}$ postexercise was associated with the amount of swelling at $8,24,48$, and $96 \mathrm{~h}$ postexercise. Swelling is a cardinal sign of inflammation; thus a relationship between swelling and some indication of inflammation was expected. The positive association between cortisol and swelling may occur because the rise in cortisol is linked to other proinflammatory elements that promote edema. Our finding that the patterns of diurnal variation among sTNFR 1 , IL-6, and cortisol were somewhat parallel is consistent with this suggestion.

Loss of strength did not associate with the inflammatory process in the present investigation. Loss of strength was expected to associate with inflammation because loss of function is considered to be one of the best indications of tissue damage $(7,37)$. That is, we expected proportionality between the amount of tissue injury and the indications of inflammation in the plasma. Additionally, significant correlations between isometric strength loss and other indications of muscle damage, including CK, soreness, and swelling, have been reported following high-force eccentric exercise similar to that in the present investigation (20). However, it may be that neutrophils are the key inflammatory component responding to primary muscle damage and promoting secondary muscle damage (32) and that the inflammatory mediators measured, IL-6 and sTNFR1, are not tightly linked to the activity of neutrophils 
(17). Regardless, higher levels of IL-6 and sTNFR1 following eccentric exercise were independent of the amount of strength lost during and in the days following the exercise.

In conclusion, we detected similar diurnal pattern for cortisol, sTNFR1, and IL-6 with highest levels at 7:00 AM followed by decreased concentrations during the day. This may be an important methodological consideration for future investigations. We compared sTNFR1, IL-6, CRP, and cortisol responses following high-force eccentric exercise with a nonexercise control condition and determined that STNFR1 is higher within the first $24 \mathrm{~h}$ postexercise and that there is a distinct peak in plasma IL-6 levels $8 \mathrm{~h}$ postexercise. Thus plasma indications of early inflammatory events are detectable in the plasma after eccentric exercise with a relatively small muscle mass. Of the muscle damage indicators measured, soreness and swelling had low associations with inflammatory mediators and are the most likely to be manifestations of secondary muscle damage driven by the inflammatory process. Conversely, loss of strength appears to have little association with the inflammation mediators measured and may be more closely linked to primary muscle damage. Overall, we conclude that while both inflammation and muscle damage are induced by high-force eccentric exercise, the inflammatory processes underlying higher sTNFR1 and IL-6 in the plasma have a low association with indirect indications of muscle damage.

\section{GRANTS}

This work was supported by a grant from the American Heart Association Pacific Mountain Affiliate to M. P. Miles.

\section{REFERENCES}

1. Aderka D, Sorkine P, Abu-Abid S, Lev D, Setton A, Cope AP, Wallach D, Klausner J. Shedding kinetics of soluble tumor necrosis factor (TNF) receptors after systemic TNF leaking during isolated limb perfusion. Relevance to the pathophysiology of septic shock. J Clin Invest 101: 650-659, 1998.

2. Beutler BA, Milsark IW, Cerami A. Cachectin/tumor necrosis factor: production, distribution, and metabolic fate in vivo. J Immunol 135: 3972-3977, 1985.

3. Bruunsgaard H, Galbo H, Halkjaer-Kristensen J, Johansen TL, MacLean DA, Pedersen BK. Exercise-induced increase in serum interleukin-6 in humans is related to muscle damage. J Physiol 499: 833-841, 1997.

4. Cannon JG, St. Pierre BA. Cytokines in exertion-induced skeletal muscle injury. Mol Cell Biochem 179: 159-167, 1998.

5. Clarkson PM, Hubal MJ. Are women less susceptible to exerciseinduced muscle damage? Curr Opin Clin Nutr Metab Care 4: 527-531, 2001.

6. Craig CL, Marshall AL, Sjostrom M, Bauman AE, Booth ML, Ainsworth BE, Pratt M, Ekelund U, Yngve A, Sallis JF, Oja P. International physical activity questionnaire: 12-country reliability and validity. Med Sci Sports Exerc 35: 1381-1395, 2003.

7. Faulkner JA, Brooks SV, Opiteck JA. Injury to skeletal muscle fibers during contractions: conditions of occurrence and prevention. Phys Ther 73: 911-921, 1993.

8. Fielding RA, Manfredi TJ, Ding W, Fiatarone MA, Evans WJ, Cannon JG. Acute phase response in exercise. III. Neutrophil and IL-1 $\beta$ accumulation in skeletal muscle. Am J Physiol Regul Integr Comp Physiol 265: R166-R172, 1993.

9. Haack M, Pollmacher T, Mullington JM. Diurnal and sleep-wake dependent variations of soluble TNF- and IL-2 receptors in healthy volunteers. Brain Behav Immun 18: 361-367, 2004.

10. Hamada K, Vannier E, Sacheck JM, Witsell AL, Roubenoff R. Senescence of human skeletal muscle impairs the local inflammatory cytokine response to acute eccentric exercise. FASEB J 19: 264-266, 2005.

11. Hellsten Y, Frandsen U, Orthenblad N, Sjodin B, Richter EA. Xanthine oxidase in human skeletal muscle following eccentric exercise: a role in inflammation. J Physiol 498: 239-248, 1997.
12. Hermann C, von Aulock S, Dehus O, Keller M, Okigami H, Gantner F, Wendel A, Hartung T. Endogenous cortisol determines the circadian rhythm of lipopolysaccharide- but not lipoteichoic acid-inducible cytokine release. Eur J Immunol 36: 371-379, 2006.

13. Hirose L, Nosaka K, Newton M, Laveder A, Kano M, Peake J, Suzuki K. Changes in inflammatory mediators following eccentric exercise of the elbow flexors. Exerc Immunol Rev 10: 75-90, 2004.

14. Liebmann PM, Reibnegger G, Lehofer M, Moser M, Purstner P, Mangge H, Schauenstein K. Circadian rhythm of the soluble p75 tumor necrosis factor (sTNF-R75) receptor in humans-a possible explanation for the circadian kinetics of TNR-alpha effects. Int Immunol 10: 13931396, 1998.

15. MacIntyre DL, Sorichter S, Mair J, Berg A, McKenzie DC. Markers of inflammation and myofibrillar proteins following eccentric exercise in humans. Eur J Appl Physiol 84: 180-186, 2001.

16. Meier-Ewert HK, Ridker PM, Rifai N, Price N, Dinges DF, Mullington JM. Absence of diurnal variation of C-reactive protein concentrations in healthy human subjects. Clin Chem 47: 426-430, 2001.

17. Miles MP. Neuroendocrine modulation of the immune system with exercise and muscle damage. In: The Endocrine System in Sports and Exercise, edited by Kraemer WJ, Rogol AD. Oxford, UK: Blackwell, 2005, p. 345-367.

18. Miles MP, Clarkson PM. Exercise-induced muscle pain, soreness, and cramps. J Sports Med Phys Fitness 34: 203-216, 1994.

19. Miles MP, Pearson SD, Andring JM, Kidd JR, Volpe SL. Effect of carbohydrate intake during recovery from eccentric exercise on interleukin-6 and muscle damage markers. Int J Sport Nutr Exercise Metab 17: 507-520, 2007.

20. Nosaka K, Chapman D, Newton M, Sacco P. Is isometric strength loss immediately after eccentric exercise related to changes in indirect markers of muscle damage? Appl Physiol Nutr Metab 31: 313-319, 2006.

21. Nosaka K, Clarkson PM, McGuiggin ME, Byrne JM. Time course of muscle adaptation after high force eccentric exercise. Eur J Appl Physiol Occup Physiol 63: 70-76, 1991.

22. Nosaka K, Sakamoto K, Newton M, Sacco P. How long does the protective effect on eccentric exercise-induced muscle damage last? Med Sci Sports Exerc 33: 1490-1495, 2001.

23. Paulsen G, Benestad HB, Strom-Gundersen I, Morkrid L, Lappegard KT, Raastad T. Delayed leukocytosis and cytokine response to high-force eccentric exercise. Med Sci Sports Exerc 37: 1877-1883, 2005.

24. Peake JM, Nosaka K, Muthalib M, Suzuki K. Systemic inflammatory responses to maximal versus submaximal lengthening contractions of the elbow flexors. Exerc Immunol Rev 12: 72-85, 2006.

25. Pearson TA, Mensah GA, Hong Y, Smith SC Jr. CDC/AHA Workshop on Markers of Inflammation and Cardiovascular Disease: Application to Clinical and Public Health Practice: overview. Circulation 110: e543e544, 2004.

26. Pedersen BK, Steensberg A, Schjerling P. Muscle-derived interleukin-6: possible biological effects. J Physiol 536: 329-337, 2001.

27. Petrovsky N, Harrison LC. The chronobiology of human cytokine production. Int Rev Immunol 16: 635-649, 1998.

28. Petrovsky N, McNair P, Harrison LC. Diurnal rhythms of pro-inflammatory cytokines: regulation by plasma cortisol and therapeutic implications. Cytokine 10: 307-312, 1998.

29. Saghizadeh M, Ong JM, Garvey WT, Henry RR, Kern PA. The expression of TNF alpha by human muscle. Relationship to insulin resistance. J Clin Invest 97: 1111-1116, 1996.

30. Smith LL, Anwar A, Fragen M, Rananto C, Johnson R, Holbert D. Cytokines and cell adhesion molecules associated with high-intensity eccentric exercise. Eur J Appl Physiol 82: 61-67, 2000.

31. Smith LL, Miles MP. Exercise-induced muscle injury and inflammation. In: Exercise and Sport Science, edited by Garrett WE, Kirkendall DT. Philadelphia, PA: Lippincott Williams Wilkins, 2000, p. 401-411.

32. Tidball JG. Inflammatory processes in muscle injury and repair. Am J Physiol Regul Integr Comp Physiol 288: R345-R353, 2005.

33. Toft AD, Jensen LB, Bruunsgaard H, Ibfelt T, Halkjaer-Kristensen J, Febbraio M, Pedersen BK. Cytokine response to eccentric exercise in young and elderly humans. Am J Physiol Cell Physiol 283: C289-C295, 2002.

34. Tomiya A, Aizawa T, Nagatomi R, Sensui H, Kokubun S. Myofibers express IL-6 after eccentric exercise. Am J Sports Med 32: 503-508, 2004.

35. Vgontzas AN, Papanicolaou DA, Bixler EO, Lotsikas A, Zachman K, Kales A, Prolo P, Wong ML, Licinio J, Gold PW, Hermida RC, Mastorakos G, Chrousos GP. Circadian interleukin-6 secretion and 
quantity and depth of sleep. J Clin Endocrinol Metab 84: 2603-2607, 1999.

36. Vigushin DM, Pepys MB, Hawkins PN. Metabolic and scintigraphic studies of radioiodinated human C-reactive protein in health and disease. J Clin Invest 91: 1351-1357, 1993.
37. Warren GL, Lowe DA, Armstrong RB. Measurement tools used in the study of eccentric contraction-induced injury. Sports Med 27: 43-59, 1999.

38. Willoughby DS, McFarlin B, Bois C. Interleukin-6 expression after repeated bouts of eccentric exercise. Int J Sports Med 24: 15-21, 2003.

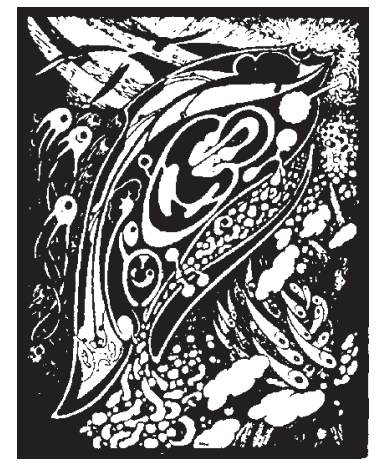

